\title{
Comparing the toxicity of two fumigants to insects from the field vs laboratory - does insect origin matter?
}

\author{
A.J. Najar-Rodriguez, M.K.D. Hall, C.R. Wilks, A.R. Adlam, S. Brierley, S. Burgess and G.K. Clare \\ The New Zealand Institute for Plant \& Food Research Limited, Private Bag 11600, Palmerston North \\ Corresponding author: adriana.najar-rodriguez@plantandfood.co.nz
}

The golden-haired bark beetle, Hylurgus ligniperda, is one of the most common insects normally associated with New Zealand export logs. Here we tested the dose-mortality responses of H. ligniperda adults, from two different origins (field vs laboratory), to methyl bromide (MB) - the most widely used fumigant worldwide and ethanedinitrile (EDN), a new fumigant currently being considered as very promising for $\mathrm{MB}$ replacement. Naked insects were fumigated with either $\mathrm{MB}$ or $\mathrm{EDN}$ at $10^{\circ} \mathrm{C}$ for 4 and 3 hours, respectively. Adults from the laboratory had been reared on an artificial diet and under controlled conditions for over 10 generations at the time of the experiments. Field adults, on the other hand, had been recently collected from Lindgren funnel traps with lures of alpha-pinene and ethanol. Our results showed that there is a significant difference in the tolerance to the two fumigants tested according to the origin of the insects, with field-collected adults being less tolerant to MB and EDN than laboratory-reared ones. The implications of our results for the development of disinfestation schedules for New Zealand export logs will be discussed.

\section{Is glyphosate-resistant ryegrass resistant to paraquat?}

\author{
H. Ghanizadeh and K.C. Harrington
}

Institute of Agriculture and Environment, Massey University, PB 11-222, Palmerston North 4442, New Zealand

Corresponding author: K.Harrington@massey.ac.nz

Sequestration of herbicide into vacuoles is considered to be the main mechanism of resistance to both glyphosate and paraquat worldwide. In New Zealand, the first case of glyphosate resistance was found in ryegrass (Lolium) species, and the restricted herbicide translocation was found to be the main mechanism of resistance in the studied populations, presumably through sequestration. Overseas researchers hypothesised that the mechanism responsible for glyphosate resistance could also cause resistance to paraquat. We examined this hypothesis by comparing a known glyphosate-resistant population of perennial ryegrass with a known susceptible population after spraying with different rates (25-800 $\mathrm{g}$ ai/ha) of paraquat. The glyphosate-resistant population responded similarly to the susceptible population at the different rates of paraquat application. This result suggests that the restricted glyphosate translocation mechanism does not necessarily lead to paraquat resistance. These results also suggest that paraquat could be useful for controlling ryegrass when glyphosate resistance has evolved and the application of paraquat is permitted. 